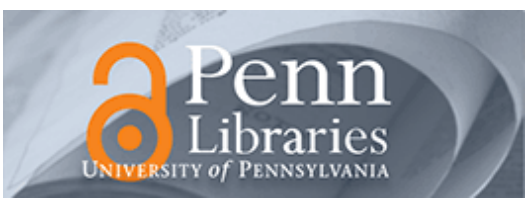

University of Pennsylvania

ScholarlyCommons

8-14-2014

\title{
The Key Role of Caregiver Confidence in the Caregiver's Contribution to Self-Care in Adults with Heart Failure
}

Ercole Vellone

Fabio D'Agostino

Harleah G. Buck

Roberta Fida

Carlo F. Spatola

See next page for additional authors

Follow this and additional works at: https://repository.upenn.edu/nrs

Part of the Behavioral Medicine Commons, Cardiology Commons, Cardiovascular Diseases

Commons, Circulatory and Respiratory Physiology Commons, Medical Humanities Commons, Nursing

Commons, and the Preventive Medicine Commons

\section{Recommended Citation}

Vellone, E., D'Agostino, F., Buck, H. G., Fida, R., Spatola, C. F., Petruzzo, A., Alvaro, R., \& Riegel, B. (2014). The Key Role of Caregiver Confidence in the Caregiver's Contribution to Self-Care in Adults with Heart Failure. European Journal of Cardiovascular Nursing, 14 (5), 372-381. http://dx.doi.org/10.1177/ 1474515114547649

This paper is posted at ScholarlyCommons. https://repository.upenn.edu/nrs/182

For more information, please contact repository@pobox.upenn.edu. 


\title{
The Key Role of Caregiver Confidence in the Caregiver's Contribution to Self-Care in Adults with Heart Failure
}

\author{
Abstract \\ Background: \\ Caregivers play an important role in contributing to heart failure (HF) patients' self-care but no prior \\ studies have examined the caregivers' contributions to HF patients' self-care and no prior studies have \\ examined potential determinants of the caregivers' contribution to HF patients' self-care.
}

Aims:

The purpose of this study was to describe the caregivers' contribution to HF patients' self-care and identify its determinants.

Methods:

The study design involved a secondary analysis of cross-sectional data. Caregivers' contributions were measured with the Caregiver's Contribution to Self-care of HF Index (CC-SCHFI) which measures the caregiver's contribution to self-care maintenance and management and caregiver confidence in contributing to HF patient's self-care. Potential determinants were measured using a socio-demographic questionnaire completed by caregivers and patients, and patient clinical data was obtained from the medical record.

Results:

Data from 515 caregiver/patient dyads were analyzed. Most (55.5\%) patients were male (mean age 75.6 years) and most (52.4\%) caregivers were female (mean age, 56.6 years). The caregivers' contribution to patients' self-care maintenance was low in weight monitoring and physical activity but higher in checking ankles, advising on low-salt foods and taking medicines. The caregivers' contribution to patients' self-care management was low in symptom recognition. When symptoms were recognized, caregivers advised patients to reduce fluids and salt and call the provider but rarely advised to take an extra diuretic. Caregiver confidence in the ability to contribute to patient self-care explained a significant amount of variance in the caregiver's contribution.

Conclusion:

These findings suggest that caregivers in this sample did not contribute meaningfully to HF self-care. Providers should educate both HF patients and caregivers. Interventions that improve caregiver confidence have the potential to successfully increase the caregivers' contribution to patients' self-care.

\section{Keywords}

caregivers, heart failure, self-efficacy, self-care

\section{Disciplines}

Behavioral Medicine | Cardiology | Cardiovascular Diseases | Circulatory and Respiratory Physiology | Medical Humanities | Medicine and Health Sciences | Nursing | Preventive Medicine

\section{Author(s)}

Ercole Vellone, Fabio D'Agostino, Harleah G. Buck, Roberta Fida, Carlo F. Spatola, Antonio Petruzzo, Rosaria Alvaro, and Barbara Riegel 
Ercole Vellone, RN, MSN, PhD student

Research Fellow

Department of Biomedicine and Prevention

University of Rome Tor Vergata, Rome, Italy

Fabio D'Agostino, RN, MSN, PhD student

Research Fellow

Department of Biomedicine and Prevention

University of Rome Tor Vergata, Rome, Italy

Harleah G. Buck, RN, PhD, CHPN

Assistant Professor

The Pennsylvania State University College of Nursing, University Park, USA

Roberta Fida, $\mathrm{PhD}$

Assistant Professor

Department of Psychology

Sapienza University of Rome, Italy

Carlo F. Spatola, RN, MSN, PhD student

Department of Biomedicine and Prevention

University of Rome Tor Vergata, Rome, Italy

Antonio Petruzzo,

RN, MSN, PhD student

Department of Biomedicine and Prevention

University of Rome Tor Vergata, Rome, Italy

Rosaria Alvaro, RN, MSN

Associate Professor

Department of Biomedicine and Prevention

University of Rome Tor Vergata, Rome, Italy

Barbara Riegel, RN, DNSc, FAHA, FAAN

Professor and Edith Clemmer Steinbright Chair of Gerontology

School of Nursing, University of Pennsylvania

Philadelphia, PA USA

Corresponding Author

Ercole Vellone

Department of Biomedicine and Prevention

University of Rome Tor Vergata

Via Montpellier, 1 - Rome 00133, Italy

Phone: + 390672596802

Fax: + 390672596961

Email: ercole.vellone@uniroma2.it 


\begin{abstract}
Background: Caregivers play an important role in contributing to Heart Failure (HF) patients' self-care but no prior studies have examined caregiver contributions to patient's HF self-care and no prior studies have examined potential determinants of caregiver contributions to HF patient self-care.
\end{abstract}

Aims: To describe caregiver contribution (CC) to HF patients' self-care and identify its determinants.

Methods: A secondary analysis of cross-sectional data. Caregiver contributions were measured with the Caregiver's Contribution to Self-care of HF Index (CC-SCHFI) which measures CC to self-care maintenance, management and confidence. Potential determinants were measured using a socio-demographic questionnaire completed by caregivers and patients and patient clinical data obtained from the medical record.

Results: Data from 515 caregiver/patient dyads were analyzed. Most (55.6\%) patients were male (mean age 75.6 years) and most (55.6\%) caregivers were female (mean age, 56.6 years). CC to patients' self-care maintenance was low in weight monitoring and physical activity but higher in checking ankles, advising on low-salt foods and taking medicines. $\mathrm{CC}$ to patients' self-care management was low in symptom recognition. When symptoms were recognized, caregivers advised patients to reduce fluids and salt and call the provider but rarely advised to take an extra diuretic. Caregiver confidence in the ability to contribute to patient selfcare explained a significant amount of variance in CC.

Conclusion: These findings suggest that caregivers in this sample did not contribute meaningfully to HF selfcare. Providers should educate both HF patients and caregivers. Interventions that improve caregiver confidence have the potential to successfully increase CC to patients' self-care.

Key words: Caregivers, Heart Failure, Self-efficacy, Self-care 


\section{Introduction}

Heart Failure (HF) is a common syndrome in developed countries with prevalence rates between 0.4 and the $2.0 \%$ in the adult population. ${ }^{1}$ In Europe, where this study was conducted, there are over 15 million people affected by HF and in the US there are over 5 million people with HF. ${ }^{1,2}$ There is an expected increase in the number of the HF patients in the near future because of the aging of the population. HF is a chronic disease characterized by poor quality of life $\mathrm{e}^{3,4}$ and high hospitalization rates. ${ }^{5}$ Prior studies have found that adherence to self-care recommendations (e.g., taking medications as prescribed, weighing every day, following a low-salt diet, exercising regularly) may improve patients' outcomes. ${ }^{6,7}$ While self-care is an important component of HF treatment, ${ }^{8}$ patients struggle to perform adequate self-care. ${ }^{9,10}$ Mobilizing informal caregivers may be one way to help patients perform self-care.

Informal caregiving is the act of providing tangible and emotional support for a loved one who is ill or disabled. Caregivers play an important, but often overlooked role in HF patients' selfcare. ${ }^{11,12}$ Caregivers' contribution to patients' self-care has been defined as the provision of time, effort, and support on behalf of another person who is performing HF self-care. ${ }^{13}$ The actual contributions to self-care by caregivers occur across a spectrum, from making recommendations to the patient on their performance of self-care to actually providing that care when the patient is unable to care for him/herself. ${ }^{13,14}$ For example, the caregiver may administer medications or prepare low-salt food when the patient is unable to do so. ${ }^{13}$

There have been no prior studies of differences in spouse and adult children caregivers of persons with HF. There was a recent study of Alzheimer's disease patients that compared burden in spouses and adult children caring for these patients. Adult children caregivers experienced higher burden than spouse caregivers despite spending less time in the caregiving role. ${ }^{15}$ These results suggest that confidence in the caregiver role may differ between the two groups. 
Even though no specific theories have as yet been developed related to caregivers' contributions to HF patients' self-care, in the recently developed Caregiver Contribution to SelfCare of Heart Failure Index (CC-SCHFI),${ }^{13}$ two dimensions of caregivers' contribution to HF patients' self-care were proposed. These dimensions reflect the patient measure of self-care on which the scale was based, the Self-Care of Heart Failure Index: $\left.{ }^{16,17} 1\right)$ caregiver contribution to self-care maintenance, which includes monitoring the patient's symptoms (e.g., helping the patient to weigh himself/herself daily), and adhering to the treatment regimen (e.g., reminding the patient to take medicine); and 2) caregiver contribution to self-care management, which includes recognizing the patient's signs and symptoms of a HF exacerbation (e.g., ankle edema), implementing actions aimed at reducing fluid overload (e.g., reducing salt in the diet, recommending fluid restriction), and evaluating the response to the implemented treatment.

Caregiver self-efficacy in contributing to the patient's self-care (e.g., confidence in the ability to keep the patient free of HF symptoms) is included in the CC-SCHFI as it is in the original scale. This process mirrors the patient-oriented situation-specific theory of HF self-care ${ }^{18}$ in proposing that caregiver task-specific confidence, or self-efficacy, contributes to patient self-care. Confidence reflects, not a domain of self-care per se, but rather a factor influencing the caregiver's contribution to patient self-care. Self-efficacy, as defined by Bandura, is the confidence in one's ability to achieve a desired result. ${ }^{19}$ Self-efficacy is modifiable with intervention and prior clinical trials with caregivers have shown that education can improve caregivers' self-efficacy and consequently caregiver and patient outcomes. ${ }^{20-22}$

Several reviews of the HF caregiving experience have been published, ${ }^{14,23-25}$ suggesting an expanding or maturing science from which to conduct further meta-analyses, meta-syntheses, or psychometric work. One particular systematic review was conducted examining what is currently known about caregiver contributions to HF patients' self-care. ${ }^{14}$ This review used the Theory of Self-care in Chronic Illness ${ }^{26}$ to classify research studies and then identified caregiver support as 
instrumental to the patient's HF self-care in the domains of maintenance (e.g., exercise, medication adherence), monitoring (e.g., blood pressure monitoring, regular weighing) and management (e.g., taking an extra diuretic). However, one limitation of these prior studies was the lack of a valid and reliable instrument specifically developed to measure caregiver contribution to HF patients' selfcare. Therefore, no prior studies have been able to examine potential determinants of caregiver contributions to patient self-care. We do know from prior studies of HF patients that sociodemographic characteristics and clinical variables are likely determinants of self-care. ${ }^{27,28}$ In addition, no prior studies have examined caregiver self-efficacy as a determinant of caregiver contributions to HF patient self-care. Helping HF patients to perform self-care can be challenging for caregivers. ${ }^{29,30}$ But, if their contributions are influenced by their self-efficacy, interventions aimed at improving caregiver self-efficacy may improve their contributions to patients' self-care and thus patients' self-care. As a valid, reliable and disease-specific instrument measuring CC to $\mathrm{HF}$ patient self-care now exists, the aims of this study were to 1) describe caregiver contributions to HF patients' self-care, 2) identify if patient and caregiver socio-demographic characteristics and patient clinical characteristics are determinants of caregivers' contribution to patient self-care, and 3) identify if caregiver self-efficacy increases the amount of explained variance in caregiver contribution to self-care beyond the patient and caregiver socio-demographic characteristics and patient clinical characteristics. Based on prior studies of patients, ${ }^{18,31,32}$ we hypothesize that caregiver self-efficacy would explain more of the variance in caregiver contribution to self-care maintenance and management than that explained by socio-demographic and clinical characteristics alone.

\section{Methods}

\section{Design}

A secondary analysis of data collected in a cross-sectional study. 
Sample, setting and procedure

Participants in this study were the primary caregivers of HF patients enrolled in a multisite study conducted in 28 Italian provinces. These provinces are located in the North, Centre and South of Italy. Inclusion criteria specified caregivers of patients with a diagnosis of HF confirmed using the diagnostic criteria of the European Society of Cardiology in $2008{ }^{33}$ and reconfirmed in $2012 ;^{2}$ and caregivers identified as such by patients at least 18 years of age who had been stable over the prior three months. Caregivers and patients were recruited during routine visits at a cardiovascular ambulatory care center.

\section{Ethical consideration}

Before data collection began, the study was approved by the Ethical Committees of each center where patients and caregivers were enrolled. Both patients and caregivers were fully informed by nurse research assistants about the study aims. Informed consent was obtained before data were collected.

\section{Measures}

Caregiver's contribution to HF self-care (CC-SCHFI). ${ }^{13}$ The CC-SCHFI is composed of three scales measuring three different dimensions: 1) the caregiver contribution to self-care maintenance scale, which has 10 items; 2) the caregiver contribution to self-care management scale, with 6 items, and 3) the caregiver confidence in contributing to self-care scale, with 6 items. Each item uses a 4-point response format. Scores on each scale are mathematically standardized to range from 0 to 100 for ease of interpretation. Higher scores indicate better self-care. The caregiver contribution to self-care management scale, as with the SCHFI v.6.2, is administered only when the patient has experienced HF symptoms in the last month. CC-SCHFI validity was established in a sample of 291 Italian HF caregivers with confirmative factor analysis which showed supportive fit indices (comparative fit indices ranging from 0.96 to 0.99 ; root mean square error of approximation 
ranging from 0.03 to 0.04$)$. CC-SCHFI validity was also tested for contrasting group validity. The CC-SCHFI was able to discriminate between caregivers able to contribute to patient self-care versus those who were not $(\mathrm{p}<0.05)$. CC-SCHFI reliability was tested with factor score determinacy coefficient and test-retest; all coefficients were $>0.70$.

Caregiver socio-demographic characteristics. A self-report survey was used to collect information on gender, age, education, marital status, employment, relationship to the patient, cohabitation or living arrangements in relation to the patient. Caregiving hours per day was measured as a continuous variable; caregivers were asked to specify the numbers of hours they spent in caregiving each day.

Patient socio-demographic and clinical characteristics. Patients' socio-demographic data included gender, age, marital status, and employment. Clinical variables collected from the medical record included New York Heart Association (NYHA) functional class, ejection fraction, and time since diagnosis measured in months. Illnesses were assessed using the Charlson Comorbidity Index $(\mathrm{CCI})^{34}$ which has established validity for predicting mortality, complications, health care resources use, length of hospital stay, discharge dispositions and cost. In 2011 the CCI was updated to a new version with 12 items, ${ }^{35}$ each of one has a possible score of 1, 2, 3 or 6 with higher score indicating higher risk for mortality. A total score can be obtained, which ranges from 0 to 24 . In this study all patients had at least a score of 2 (the score given to HF).

The Mini Mental State Examination (MMSE) ${ }^{36}$ was used to measure global cognition. The MMSE includes 19 items which assess the following areas: orientation to time and place, registration of three words, attention and calculation, recall of three words, language, and visual construction. The MMSE has been widely used in HF patients. ${ }^{37,38}$ Scores range from 0 and 30 with higher scores indicating better cognition. Cronbach's alpha of the MMSE was 0.85 in this study. 
Descriptive statistics (frequencies, mean, SD) were used to describe caregiver and patient socio-demographic characteristics and patient clinical characteristics and to describe both the items and the computed scale dimensions of the CC-SCHFI. Pearson correlation was used to identify which caregiver socio-demographic variables and which patient socio-demographic and clinical variables were correlated with the three CC-SCHFI dimensions (caregiver contribution to self-care maintenance and management and caregiver self-efficacy). Since self-care maintenance and management are theoretically distinct ${ }^{13}$ two hierarchical regression models were tested. We did that in order to examine the additive role of caregiver confidence in explaining caregiver contributions to self-care maintenance (dependent variable of the first regression) and management (dependent variable of the second regression) above and beyond caregiver socio-demographic variables and patient socio-demographic and clinical variables. Specifically, the caregiver and patient variables chosen for testing that were significantly correlated with caregiver contribution to self-care maintenance and management were entered as independent variables in the first step of each hierarchical regression model. Then caregiver confidence in their abilities to contribute to patient self-care was entered as an independent variable in the second step of the hierarchical regression. To test the hypothesis that caregiver contribution would add significant variance over and above socio-demographic and clinical variables, we considered change in $\mathrm{R}^{2}$ and the beta coefficients. Multicollinearity between the predictor variables entered into the models was assessed with the Variance Inflation Factor (VIF) and Tolerance: A VIF higher than 4 and a Tolerance lower than 0.20 are indicative of multicollinearity. ${ }^{39}$ Statistical significance was set at $p<0.05$. All data were analyzed with SPSS version 20.

\section{Results}

\section{Caregivers'Socio-demographic Characteristics}

A total of 515 caregiver and patient dyads participated in the study. Table 1 presents the caregiver socio-demographic characteristics. Caregivers were relatively young (mean age 56.6 
years, $\mathrm{SD}=14.9$ ) reflecting the large number of adult offspring caregivers. Caregivers were approximately equally distributed between female (52.4\%) and male. The level of education was equally distributed, as well, between caregivers with less than a high school education (48\%) and others with at least high school education (52\%). Most caregivers were married (72.8\%) and employed (56.5\%). Spouses and children represented more than the $85 \%$ of the sample. Among spouses and children there were no statistically significant differences in gender $(\mathrm{p}=0.82)$, but spouses were older $(79.2$ vs. 50.0 years, $p<0.001)$ and less educated $(p<0.001)$ than children. Less than half (37.7\%) of the caregivers lived with the patient and the mean number of hours of caregiving provided per day was 7.5 (SD 7.2). When we excluded those caregivers who said that they provided caregiving 24 hours per day (13.5\% of the sample), the mean and SD was 5.39 and 3.93 hours respectively.

\section{Patients' Socio-demographic and Clinical Characteristics}

Table 2 presents patients' socio-demographic and clinical characteristics. Patients were predominately older (mean age 75.6 years, $\mathrm{SD}=10.7)$ and male $(55.5 \%)$. The level of education was low with $75.2 \%$ of patients having less than a high school education. Most patients were unemployed (88.7\%) and married (55.7\%). All NYHA classes were represented in the sample but most patients (72.6\%) were in NYHA class II and III. The mean score on the CCI was 3 indicating a relatively low level of comorbidity, while the mean of score on the MMSE was 23, which denotes mild cognitive impairment.

\section{Caregiver Contribution to Self-care Maintenance and Management}

Figure 1 illustrates the caregiver contribution to self-care maintenance which had a total score of 55.9 (SD 17.9; range 0 - 100). The descriptive analysis of individual items on the caregiver contribution to self-care maintenance scale showed that more than half of the caregivers never/rarely or only sometimes recommended that the patient check his/her weight $(54.9 \%)$ or 
perform physical activity (66.6\%) or exercise (64.8\%). However, more than $60 \%$ of caregivers reported recommending that the patient check his/her ankles and eat a low-salt diet. More than $70 \%$ of caregivers recommended that the patient take medicines, try not to get sick, and keep doctor or nurse appointments (Figure 1). More than half of caregivers (56.1\%) used a system to remind patients to take their medicines.

Of the total sample, only 255 caregivers (or 50\%) reported that the patient had HF symptoms in the preceding month, allowing for administration of the caregiver contribution to selfcare management scale (caregiver actions taken to relieve HF symptoms) (Figure 2). The mean score on this scale was 58.4 (SD 18.19, range 5 - 100). More than a half of these caregivers $(54.2 \%)$ were unable to recognize the signs and symptoms of a HF exacerbation quickly or very quickly. Once recognized, most caregivers recommended that patients reduce the salt in their diet (66.7\%), drink fewer fluids (54.9\%) or call their providers (69\%). Few caregivers $(47.8 \%)$ recommended that patients take an extra diuretic. Most (69\%) caregivers felt sure of their ability to judge whether the remedy they recommended most recently was effective.

\section{Caregiver confidence in contributing to self-care}

Figure 3 illustrates caregiver confidence in contributing to patient self-care. Mean caregiver score on the self-care confidence scale was 56.9 (SD 19.3, range 11.1 - 100). Caregivers were most confident in their ability to follow treatment advice (80.6\%), evaluate the importance of symptoms (61.4\%) and evaluate if a remedy suggested to relieve symptoms worked (50.9\%). They were less confident in their ability to prevent HF symptoms (58.8\%) and do something to relieve symptoms when they occurred (53.8\%). There were no statistically significant differences in confidence between spouse and adult children caregivers (mean scores 53.94, SD 19.18 vs. 57.03, SD 19.94 respectively, $\mathrm{p}=0.19$ ). 
As shown in Table 3, variables significantly correlated with better caregiver contribution to self-care maintenance were caregiver female gender, being married to the HF patient, better NYHA functional class, longer time since diagnosis, and higher caregiver confidence. Variables significantly correlated with caregiver contribution to self-care management were younger caregiver age, fewer caregiving hours, female patient gender, single marital status of the patient, and higher caregiver confidence.

The role of caregiver confidence in explaining caregiver contribution to self-care maintenance and management

Collinearity analysis showed a VIF for all tested models $\leq 1.2$ and a Tolerance $\geq 0.84$, indicating no collinearity. Results of the two hierarchical regression analyses suggested that caregiver confidence significantly affected caregiver contribution to both self-care maintenance and to self-care management. This contribution was above that associated with the caregivers' sociodemographic variables and the patients' socio-demographic and clinical variables (Table 4). For caregiver contribution to self-care maintenance, in Model 1, the only significant predictor was time since diagnosis, which explained only $0.02 \%$ of the variance $(F=2.606, \mathrm{p} 0.035)$. Adding caregiver confidence, the model (Model 2) improved the explained variance in caregiver contribution to selfcare maintenance to $16 \%(\mathrm{~F}=15.567, \mathrm{p}=0.000)$. In Model 2 the only two variables that explained caregiver contribution to self-care maintenance were patient's time since diagnosis and caregiver confidence.

For the caregiver contribution to self-care management, in Model 1, the only significant determinant was caregiving hours. This model explained only the $6 \%$ of variance in caregiver contribution to self-care management $(F=4.489, \mathrm{p}=0.002)$. When caregiver confidence was added in Model 2, the explained variance of caregiver contribution to self-care management improved to $34 \%$. Caregiver confidence was the only significant predictor of caregiver contribution to self-care management $(\mathrm{F}=97.882, \mathrm{p}<0.001)$. Thus, our hypothesis that caregiver self-efficacy explained 
more of the variance in caregiver contribution to self-care maintenance and management beyond that explained by socio-demographic and clinical characteristics was supported.

\section{Discussion}

The aim of this study was to describe caregivers' contributions to HF patients' self-care and then to identify potential determinants of that care, testing patient and caregiver socio-demographic characteristics, patient clinical characteristics and caregiver self-efficacy. In this sample we found that self-efficacy was the primary determinant of caregivers' contributions to patients' self-care maintenance and management. Prior studies carried out in other populations with similar caregiving responsibilities have shown that higher caregiver self-efficacy is associated with better outcomes for both caregivers and patients..$^{40,41}$ But, to the best of our knowledge, this is the first study that has documented the importance of self-care self-efficacy in caregivers of HF patients.

Although caregivers were not informed contributors, they were supportive of some self-care maintenance activities. Unfortunately, they never or rarely supported some important activities such as daily weights and exercise. Of particular concern is the finding that over half of the caregivers reported that they did not quickly recognize common signs of a HF exacerbation such as shortness of breath or ankle edema. Once signs were recognized, most recommended reducing salt in the diet and fluid intake or calling the provider over an active intervention such as taking an extra diuretic. These behaviors suggest that knowledge about what self-care maintenance behaviors are most effective is insufficient in many caregivers.

This conclusion is supported by a recent meta-synthesis of 10 qualitative studies, ${ }^{23}$ where a recurrent theme in the experience of HF caregivers was "searching for support", which also included the need of caregivers to be adequately prepared for the disease. In particular, in four studies included in this meta-synthesis, caregivers complained about knowledge deficits regarding the disease and its management and did not know the importance of behavioral management strategies such as weight monitoring, physical activity, salt and fluid restriction. Of note, these 
specific needs were reported by caregivers even after 18 months of caregiving. Uncertainty in how to behave with patients also has been reported previously. ${ }^{42}$ However further studies are needed to understand other factors influencing caregiver contributions to patient self-care.

Considering self-care management, $54 \%$ of our sample of caregivers was unable to recognize symptoms of a HF exacerbation quickly. Quinn and Dunbar ${ }^{43}$ found poor congruence between caregivers and patients in symptom assessment as well as poor caregiver skills in symptom recognition. Similarly, Janseen et $\mathrm{al}^{44}$ found that caregivers tend to overestimate symptoms. Our results contribute to this small body of knowledge by reiterating the need for caregivers to learn as much as patients about how to monitor and interpret early symptoms.

Caregivers felt confident in contributing to some self-care activities (treatment adherence, evaluating the importance of symptoms and evaluating symptom remedies) but felt less confident in their ability to prevent and relieve symptoms. Preventing and relieving patients' symptoms might be difficult if caregivers lack sufficient knowledge on disease management. Studies carried out in other caregiver populations have shown that knowledge of disease management is a predictor of higher caregiver self-efficacy and better contributions to patient self-care. ${ }^{22,45}$

This is the first study that has measured the caregiver contribution to HF patient self-care with a disease-specific instrument. The CC-SCHFI provides a specific measure of the support provided to HF patients by caregivers. Data from this instrument facilitates the identification of areas where caregivers contribute more (e.g. medication regimen) and areas where caregivers contribute less (e.g. symptom recognition). Specific measurements of caregiver contribution to HF patient self-care, such as the CC-SCHFI, can be useful to guide future research and tailored interventions for HF caregivers.

This study has several limitations. Even though this was a multicenter study, a convenience sample was enrolled. A further limitation is the cross-sectional design, which allowed only the identification of correlates or determinants of self-care. Future studies should use a longitudinal 
design in order to identify true predictors of CC to self-care maintenance and management. In addition, results from this study should be generalized to other countries with caution as Italian cultural aspects may have influenced how caregivers in this sample took care of their loved ones.

\section{Conclusion}

In this study we found that self-efficacy was a unique determinant of caregiver contributions to both self-care maintenance and self-care management. According to Bandura Cognitive Theory ${ }^{19}$ self-efficacy can be improved with performance accomplishment, vicarious experience, verbal persuasion, and emotional arousal. Further studies are needed in order to test the applicability and effectiveness of interventions guided by Bandura's theory for HF caregivers.

\section{Funding}

This work was funded by the Center of Excellence for Nursing Scholarship, Rome, Italy.

\section{Conflict of Interest:}

None declared.

\section{Implication for practice}

- Providers need to strengthen the education given to HF caregivers and to understand reasons that prevent them from contributing to HF patients' self-care.

- Providers should reinforce the importance of weight monitoring and physical activity with caregivers as well as patients

- Caregiver understanding and implementation of symptom monitoring and diuretic selftitration should be assessed frequently and reinforced as needed 
- Improving caregiver self-efficacy may improve their contributions to patients' self-care and thus patients' self-care.

- Self-efficacy building activities are needed for this vital group. 


\section{References}

1. Go AS, Mozaffarian D, Roger VL, et al. Heart disease and stroke statistics--2014 update: a report from the American Heart Association. Circulation 2014; 129:e28-e292.

2. McMurray JJ, Adamopoulos S, Anker SD, et al. ESC guidelines for the diagnosis and treatment of acute and chronic heart failure 2012: The Task Force for the Diagnosis and Treatment of Acute and Chronic Heart Failure 2012 of the European Society of Cardiology. Developed in collaboration with the Heart Failure Association (HFA) of the ESC. Eur $J$ Heart Fail 2012; 14:803-869.

3. Graven LJ, Grant JS. Coping and health-related quality of life in individuals with heart failure: an integrative review. Heart Lung 2013; 42:183-194.

4. Hickey KT, Reiffel J, Sciacca RR, et al. Correlating perceived arrhythmia symptoms and quality of life in an older population with heart failure: a prospective, single centre, urban clinic study. J Clin Nurs 2013; 22:434-444.

5. Foebel AD, Heckman GA, Ji K, et al. Heart failure--related mortality and hospitalization in the year following admission to a long-term care facility: the geriatric outcomes and longitudinal decline in heart failure (GOLD-HF) study. J Card Fail 2013; 19:468-477.

6. Kato N, Kinugawa K, Nakayama E, et al. Insufficient self-care is an independent risk factor for adverse clinical outcomes in Japanese patients with heart failure. Int Heart J 2013; 54:382-389.

7. Lee KS, Lennie TA, Warden S, Jacobs-Lawson JM, Moser DK. A comprehensive symptom diary intervention to improve outcomes in patients with HF: a pilot study. J Card Fail 2013; 19:647-654.

8. Riegel B, Moser DK, Anker SD, et al. State of the science: promoting self-care in persons with heart failure: a scientific statement from the American Heart Association. Circulation $2009 ; 120: 1141-1163$. 
9. Riegel B, Driscoll A, Suwanno J, et al. Heart failure self-care in developed and developing countries. J Card Fail 2009; 15:508-516.

10. Jones CD, Holmes GM, Dewalt DA, et al. Is adherence to weight monitoring or weightbased diuretic self-adjustment associated with fewer heart failure-related emergency department visits or hospitalizations? J Card Fail 2012; 18:576-584.

11. Dunbar SB, Clark PC, Quinn C, Gary RA, Kaslow NJ. Family influences on heart failure self-care and outcomes. J Cardiovasc Nurs 2008; 23:258-265.

12. Sebern MD, Woda A. Shared care dyadic intervention: outcome patterns for heart failure care partners. West $J$ Nurs Res 2012; 34:289-316.

13. Vellone E, Riegel B, Cocchieri A, et al. Validity and Reliability of the Caregiver Contribution to Self-care of Heart Failure Index. J Cardiovasc Nurs 2013; 28:245-255.

14. Buck H, Harkness K, Wion R, et al. Caregivers' contributions to heart failure self-care: a systematic review Eur J Cardiovasc Nurs 2013.

15. Reed C, Belger M, Dell'agnello G, et al. Caregiver Burden in Alzheimer's Disease: Differential Associations in Adult-Child and Spousal Caregivers in the GERAS Observational Study. Dement Geriatr Cogn Dis Extra 2014; 4:51-64.

16. Riegel B, Lee CS, Dickson VV, Carlson B. An update on the self-care of heart failure index. J Cardiovasc Nurs 2009; 24:485-497.

17. Vellone E, Riegel B, Cocchieri A, et al. Psychometric properties of the self-care of heart failure index version 6.2. Res Nurs Health 2013; 36:500-511.

18. Riegel B, Dickson VV. A situation-specific theory of heart failure self-care. J Cardiovasc Nurs 2008; 23:190-196.

19. Bandura A. Self-efficacy: toward a unifying theory of behavioral change. Psychol Rev 1977; 84:191-215. 
20. Chan SW, Yip B, Tso S, Cheng BS, Tam W. Evaluation of a psychoeducation program for Chinese clients with schizophrenia and their family caregivers. Patient Educ Couns 2009; 75:67-76.

21. Collinge W, Kahn J, Walton T, et al. Touch, Caring, and Cancer: randomized controlled trial of a multimedia caregiver education program. Support Care Cancer 2013; 21:1405-1414.

22. Terpstra JL, Chavez LJ, Ayala GX. An intervention to increase caregiver support for asthma management in middle school-aged youth. J Asthma 2012; 49:267-274.

23. Kang X, Li Z, Nolan MT. Informal Caregivers' Experiences of Caring for Patients With Chronic Heart Failure: Systematic Review and Metasynthesis of Qualitative Studies. $J$ Cardiovasc Nurs 2011; 26:386-394 310.1097/JCN.1090b1013e3182076a3182069.

24. Molloy GJ, Johnston DW, Witham MD. Family caregiving and congestive heart failure. Review and analysis. European Journal of Heart Failure 2005; 7:592-603.

25. Dunbar SB, Clark PC, Quinn C, Gary RA, Kaslow NJ. Family influences on heart failure self-care and outcomes. Journal of Cardiovascular Nursing 2008; 23:258-265.

26. Riegel B, Jaarsma T, Stromberg A. A middle-range theory of self-care of chronic illness. ANS Adv Nurs Sci 2012; 35:194-204.

27. Cocchieri A, Riegel B, D'Agostino F, et al. Describing self-care in Italian adults with heart failure and identifying determinants of poor self-care. Eur J Cardiovasc Nurs 2014.

28. Davis KK, Dennison Himmelfarb CR, Szanton SL, Hayat MJ, Allen JK. Predictors of Heart Failure Self-care in Patients Who Screened Positive for Mild Cognitive Impairment. $J$ Cardiovasc Nurs 2014.

29. Malik FA, Gysels M, Higginson IJ. Living with breathlessness: a survey of caregivers of breathless patients with lung cancer or heart failure. Palliat Med 2013; 27:647-656.

30. Hwang B, Fleischmann KE, Howie-Esquivel J, Stotts NA, Dracup K. Caregiving for patients with heart failure: impact on patients' families. Am J Crit Care 2011; 20:431-441; quiz 442. 
31. Dickson VV, Buck H, Riegel B. Multiple comorbid conditions challenge heart failure selfcare by decreasing self-efficacy. Nurs Res 2013; 62:2-9.

32. Dickson VV, Buck H, Riegel B. A qualitative meta-analysis of heart failure self-care practices among individuals with multiple comorbid conditions. J Card Fail 2011; 17:413419.

33. Dickstein K. ESC guidelines for the diagnosis and treatment of acute and chronic heart failure 2008: application of natriuretic peptides. Reply. Eur Heart J 2008.

34. Charlson ME, Pompei P, Ales KL, MacKenzie CR. A new method of classifying prognostic comorbidity in longitudinal studies: development and validation. J Chronic Dis 1987; 40:373-383.

35. Quan H, Li B, Couris CM, et al. Updating and validating the Charlson comorbidity index and score for risk adjustment in hospital discharge abstracts using data from 6 countries. $\mathrm{Am}$ J Epidemiol 2011; 173:676-682.

36. Folstein MF, Folstein SE, McHugh PR. Mini Mental State. A practical method for grading the cognitive state of the patients for the clinicians. J Psychiatr Res 1975;12:189-198.

37. Feola M, Garnero S, Vallauri P, et al. Relationship between Cognitive Function, Depression/Anxiety and Functional Parameters in Patients Admitted for Congestive Heart Failure. Open Cardiovascular Medicine Journal 2013; 7:54-60.

38. Caminiti G, Ranghi F, De Benedetti S, et al. Cognitive impairment affects physical recovery of patients with heart failure undergoing intensive cardiac rehabilitation. Rehabilitation Research and Practice 2012; 2012:218928.

39. Fox J. Regression diagnostics. Thousand Oaks, CA: Sage; 1991.

40. Cheng ST, Lam LC, Kwok T, Ng NS, Fung AW. Self-efficacy is associated with less burden and more gains from behavioral problems of Alzheimer's disease in Hong Kong Chinese caregivers. Gerontologist 2013; 53:71-80. 
41. Northouse LL, Mood DW, Schafenacker A, et al. Randomized clinical trial of a brief and extensive dyadic intervention for advanced cancer patients and their family caregivers. Psychooncology 2013; 22:555-563.

42. Essue BM, Jowsey $\mathrm{T}$, Jeon $\mathrm{YH}$, et al. Informal care and the self-management partnership: implications for Australian health policy and practice. Aust Health Rev 2010; 34:414-422.

43. Quinn C, Dunbar SB, Higgins M. Heart failure symptom assessment and management: can caregivers serve as proxy? J Cardiovasc Nurs 2010; 25:142-148.

44. Janssen DJ, Spruit MA, Wouters EF, Schols JM. Symptom distress in advanced chronic organ failure: disagreement among patients and family caregivers. J Palliat Med 2012; $15: 447-456$.

45. Huang HL, Kuo LM, Chen YS, et al. A home-based training program improves caregivers' skills and dementia patients' aggressive behaviors: a randomized controlled trial. Am J Geriatr Psychiatry 2013; 21:1060-1070. 
Table 1. Caregivers' Socio-demographic Characteristics $(n=515)$

\begin{tabular}{|c|c|}
\hline Variables & $\mathrm{n}(\%)$ \\
\hline \multicolumn{2}{|l|}{ Gender } \\
\hline Male & $245(47.6)$ \\
\hline Female & $270(52.4)$ \\
\hline Age, mean (SD) & $56.6(14.9)$ \\
\hline \multicolumn{2}{|l|}{ Education } \\
\hline Elementary & $80(15.6)$ \\
\hline Middle school & $167(32.4)$ \\
\hline Professional school & $70(13.6)$ \\
\hline High school & $146(28.3)$ \\
\hline University degree & $52(10.1)$ \\
\hline \multicolumn{2}{|l|}{ Marital Status } \\
\hline Married & $375(72.8)$ \\
\hline Single & $74(14.4)$ \\
\hline Widowed & $24(4.6)$ \\
\hline Divorced & $42(8.2)$ \\
\hline \multicolumn{2}{|l|}{ Profession } \\
\hline Employed & $291(56.5)$ \\
\hline Unemployed & $224(43.5)$ \\
\hline \multicolumn{2}{|l|}{ Relationship with patient } \\
\hline Spouse & $173(33.6)$ \\
\hline Child & $271(52.6)$ \\
\hline Friend & $14(2.7)$ \\
\hline Nephew/niece & $23(4.5)$ \\
\hline Brother/sister & $11(2.1)$ \\
\hline Other relative & $23(4.5)$ \\
\hline Caregiver living with patient & $194(37.7)$ \\
\hline Hours of caregiving per day, mean (SD) & $7.5(7.2)$ \\
\hline
\end{tabular}


Table 2. Patients' Socio-demographic and Clinical Characteristics $(\mathrm{n}=515)$

\begin{tabular}{|c|c|}
\hline Variables & $\mathrm{n}(\%)$ \\
\hline \multicolumn{2}{|l|}{ Gender } \\
\hline Male & $286(55.5)$ \\
\hline Female & $229(44.5)$ \\
\hline Age (mean, SD) & $75.6(10.7)$ \\
\hline \multicolumn{2}{|l|}{ Education } \\
\hline Elementary & $270(52.5)$ \\
\hline Middle school & $117(22.7)$ \\
\hline Professional school & $45(8.7)$ \\
\hline High school & $65(12.6)$ \\
\hline University degree & $18(3.5)$ \\
\hline \multicolumn{2}{|l|}{ Marital Status } \\
\hline Married & $287(55.7)$ \\
\hline Single & $17(3.3)$ \\
\hline Widowed & $183(35.5)$ \\
\hline Divorced & $28(5.4)$ \\
\hline \multicolumn{2}{|l|}{ Profession } \\
\hline Employed & $58(11.3)$ \\
\hline Unemployed & $457(88.7)$ \\
\hline \multicolumn{2}{|l|}{ New York Heart Association class } \\
\hline I & $94(18.2)$ \\
\hline II & $192(37.3)$ \\
\hline III & $182(35.3)$ \\
\hline IV & $47(9.2)$ \\
\hline Ejection fraction (mean, SD) & $44.1(10.7)$ \\
\hline $\begin{array}{l}\text { Time since diagnosis (months) (median, } \\
\text { interquartile range) }\end{array}$ & $45.5(24-72)$ \\
\hline CCI (mean, SD) & $3.05(1.3)$ \\
\hline MMSE (mean, SD) & $23.4(6.7)$ \\
\hline
\end{tabular}


Table 3. Correlations with CC-SC Maintenance and CC-SC Management

\begin{tabular}{|c|c|c|}
\hline & $\begin{array}{c}\text { CC-SC } \\
\text { Maintenance }\end{array}$ & $\begin{array}{c}\text { CC-SC } \\
\text { Management }\end{array}$ \\
\hline Caregiver gender $(0=$ Male; $1=$ Female $)$ & $0.10^{*}$ & 0.01 \\
\hline Caregiver age (from 20 to 88 ) & 0.0 & $-0.16^{*}$ \\
\hline $\begin{array}{l}\text { Caregiver education (from } 1=\text { Elementary to } 5=\text { University } \\
\text { degree) }\end{array}$ & -0.06 & -0.04 \\
\hline Caregiver marital status $(0=$ without partner; $1=$ with partner $)$ & $0.10^{*}$ & 0.011 \\
\hline Caregiver Job $(0=$ unemployed; $1=$ employed $)$ & -0.02 & -0.03 \\
\hline Do You live with Patient? $(0=$ no; $1=$ yes $)$ & 0.02 & 0.04 \\
\hline $\begin{array}{l}\text { How many hours do you care for the patient in a day? (from } 1 \\
\text { to } 24 \text { ) }\end{array}$ & -0.01 & $-0.21 * *$ \\
\hline Patient Gender $(0=$ Male; $1=$ Female $)$ & 0.03 & $0.12 *$ \\
\hline Patient Age (from 29 to 96 ) & -0.05 & -0.05 \\
\hline Patient's marital status ( $0=$ without partner; $1=$ with partner $)$ & 0.04 & $-0.16^{* *}$ \\
\hline Patient's Job ( $0=$ unemployed; $1=$ employed $)$ & -0.02 & 0.04 \\
\hline NYHA Class ( from 1 to 4 ) & $0.10^{*}$ & -0.09 \\
\hline EF (from 20 to 90 ) & 0.01 & 0.08 \\
\hline Time since diagnosis (months) (from 1 to 240 ) & $0.12 * *$ & -0.01 \\
\hline CCI (from 1 to 11 ) & 0.09 & -0.08 \\
\hline MMSE (from 10 to 30 ) & -0.02 & 0.01 \\
\hline Caregiver confidence (from 0 to 100 ) & $0.42 * *$ & $0.59 * *$ \\
\hline CC-SC Maintenance (from 0 to 100 ) & - & $0.44 * *$ \\
\hline
\end{tabular}

Note: Numbers being presented are correlation coefficients; all comparison were against the variable coded 0 .

$\mathrm{EF}=$ Ejection Fraction; $\mathrm{CCI}=$ Charlson Comorbidity Index; MMSE $=$ Mini Mental State Examination; CC-

$\mathrm{SC}=$ caregiver contribution to self-care; $*<0.05 ; * *<0.01$ 
Figure 1. Percentages of responses per each Likert point to Caregiver contribution to self-care maintenance scale

How often do you recommend to the person you care for the following things? (Or, how often do you do these activities because the person you care for is not able to do them).

$$
0 \% \quad 50 \% \quad 100 \%
$$

(1) Weigh Daily

(2) Check ankles for swelling

\begin{tabular}{|c|c|c|c|c|}
\hline 18.0 & \multicolumn{2}{|c|}{36.9} & 34.2 & 10.9 \\
\hline 10.3 & 27.6 & 42.9 & 19.2 \\
\hline
\end{tabular}

(3) Try to avoid getting sick (get a flu shot, avoid ill people)

(4) Do some phy sical activity

(5) Keep doctor or nurse appointments

(6) Eat a low-salt diet

(7) Exercise for 30 minutes

(8) Remember to take medicines

(9) Ask for a low-salt items when eating out or visiting others

(10) Use a system (pill-box, reminder) to help him/her remember to take medicines

\begin{tabular}{|c|c|c|c|c|}
\hline \begin{tabular}{|l|l|}
10.7 & 16.9
\end{tabular} & & & \multicolumn{2}{|c|}{33.2} \\
\hline 24.3 & \multicolumn{2}{|c|}{36.3} & 23.7 & 15.7 \\
\hline \begin{tabular}{|l|l|}
9.9 & 10.3 \\
\end{tabular} & \multicolumn{2}{|l|}{31.1} & \multicolumn{2}{|l|}{48.7} \\
\hline 21.5 & \multicolumn{2}{|c|}{34.8} & \multicolumn{2}{|c|}{31.5} \\
\hline 32.4 & \multicolumn{2}{|c|}{32.4} & 22.7 & 12.4 \\
\hline 14.4 & 25. & \multicolumn{3}{|c|}{44.9} \\
\hline 19.4 & 23.7 & 28.5 & \multicolumn{2}{|c|}{28.3} \\
\hline 24.7 & 19.2 & 27.6 & & 8.5 \\
\hline
\end{tabular}

$\square$ Never or rarely $\square$ Sometimes $\square$ Frequently $\square$ Always or daily

Note. Numbers in bars are percentages of responses per each Likert point 
Figure 2. Percentages of responses per each Likert point to caregiver contribution to self-care management scale

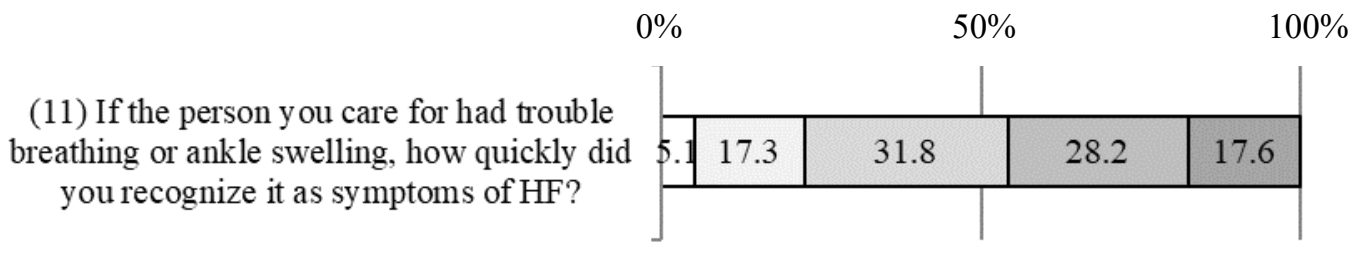

口I did not recognize it $\square$ Not quickly $\square$ Somewhat Quickly $\square$ Quickly $\square$ Very Quickly

If the person you care for has trouble breathing or ankle swelling, how likely are you to recommend (or do) one of these remedies?

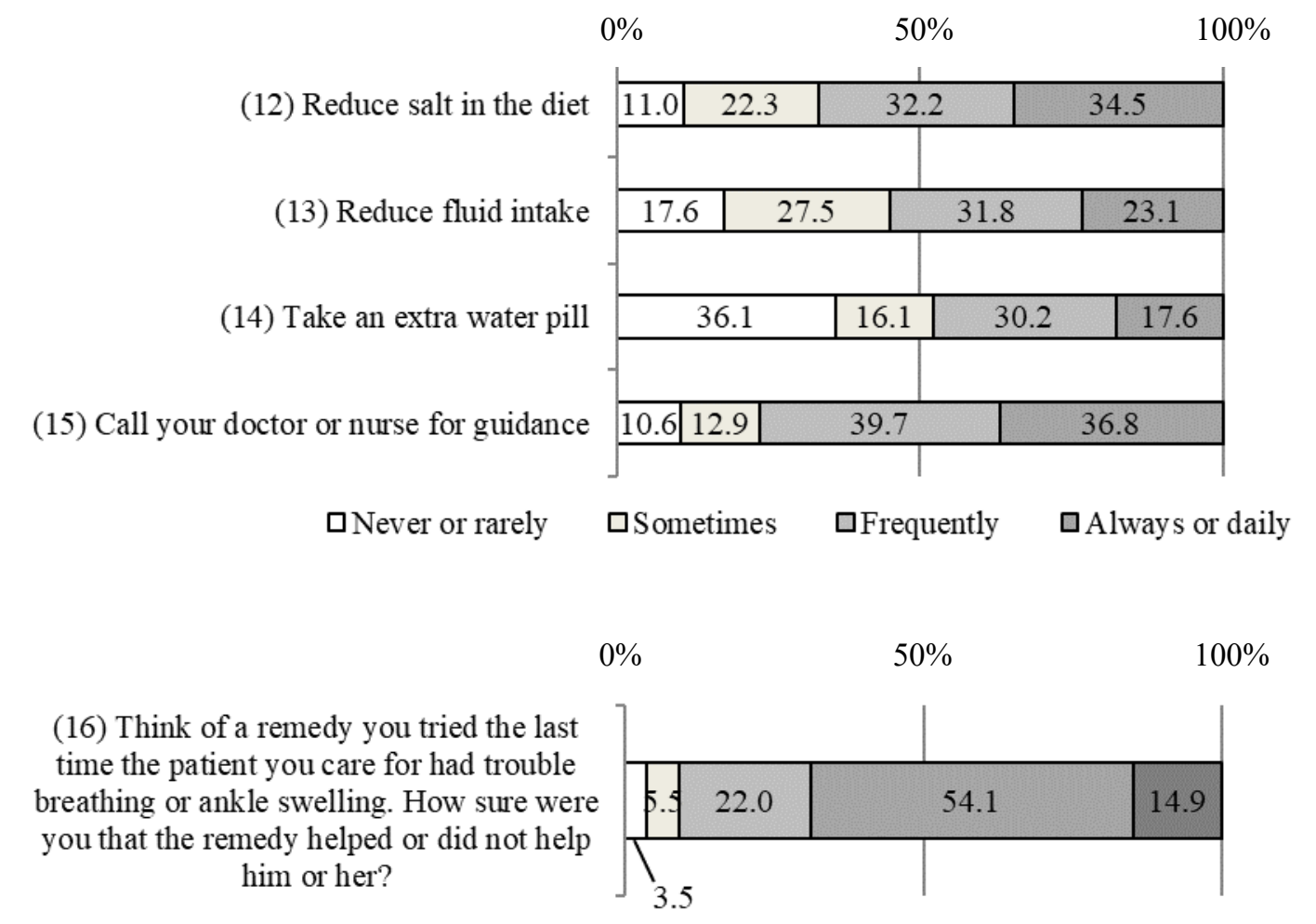

口I did not recognize it $\square$ Not quickly $\square$ Somewhat Quickly $\square$ Quickly $\square$ Very Quickly 
Figure 3. Percentages of responses per each Likert point to caregiver confidence in contributing to self-care

In reference to the person you care for, in general, how confident are you that you can:

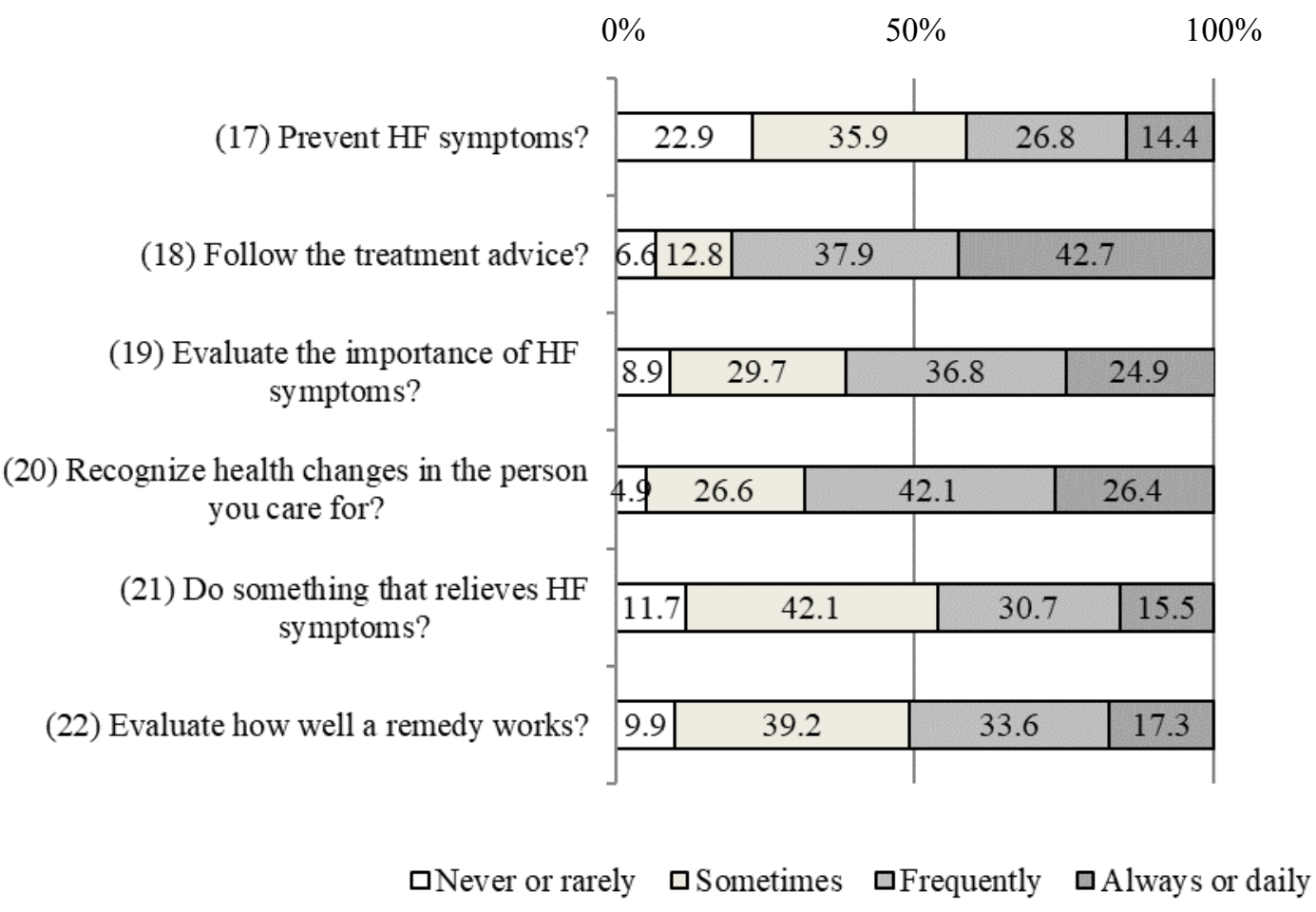


Table 4. The role of caregiver confidence in explaining Self-care Maintenance and Management

\begin{tabular}{|c|c|c|c|c|}
\hline & \multicolumn{2}{|l|}{ Model 1} & \multicolumn{2}{|c|}{ Model 2} \\
\hline & Standardized $\beta$ & $p$ & Standardized $\beta$ & $p$ \\
\hline \multicolumn{5}{|c|}{ Dependent variable: Caregiver Contribution to Self-care Maintenance } \\
\hline $\begin{array}{l}\text { Caregiver gender }(0=\text { male; } 1= \\
\text { female })\end{array}$ & 0.000 & 0.998 & -0.008 & 0.860 \\
\hline Caregiver marital status & & & & \\
\hline $\begin{array}{l}(0=\text { without partner; } 1=\text { with } \\
\text { partner })\end{array}$ & 0.019 & 0.698 & 0.021 & 0.641 \\
\hline NYHA class & 0.055 & 0.296 & 0.045 & 0.357 \\
\hline Month of illness & 0.125 & 0.018 & 0.097 & 0.049 \\
\hline Caregiver confidence & & & 0.370 & $<0.001$ \\
\hline $\mathrm{R}^{2}$ & 0.025 & & 0.160 & \\
\hline Adjusted $\mathrm{R}^{2}$ & 0.015 & & 0.150 & \\
\hline F & 2.606 & 0.035 & 15.567 & $<0.001$ \\
\hline \multicolumn{5}{|c|}{ Dependent variable: Caregiver Contribution to Self-care Management } \\
\hline Caregiver age & -0.065 & 0.344 & -0.013 & 0.825 \\
\hline Caregiving hours & -0.147 & 0.024 & -0.079 & 0.152 \\
\hline $\begin{array}{l}\text { Patient gender }(0=\text { male; } 1= \\
\text { female })\end{array}$ & -0.050 & 0.444 & -0.052 & 0.341 \\
\hline Patient's marital status & & & & \\
\hline $\begin{array}{l}(0=\text { without partner; } 1=\text { with } \\
\text { partner })\end{array}$ & -0.115 & 0.099 & -0.051 & 0.386 \\
\hline Caregiver confidence & & & 0.543 & $<0.001$ \\
\hline $\mathrm{R}^{2}$ & 0.065 & & 0.342 & \\
\hline Adjusted $R^{2}$ & 0.050 & & 0.329 & \\
\hline $\mathrm{F}$ & 4.489 & 0.002 & 97.882 & $<0.001$ \\
\hline
\end{tabular}

Note. All comparison were against the variable coded 0 . 